Bangladesh J. Plant Taxon. 27(2): 461-465, 2020 (December)

- Short communication

(C) 2020 Bangladesh Association of Plant Taxonomists

\title{
ELUCIDATING DIFFERENCES BETWEEN TWO CONFUSING SHOREA CONTORTA S. VID AND PENTACME MINDANENSIS FOXW. SPECIES OF DIPTEROCARPACEAE VIA LEAF MORPHOMETRICS: AN INITIAL INVESTIGATION
}

\author{
Kean Roe F. Mazo* and Lowell G. Aribal ${ }^{1}$ \\ Forestry Department, College of Forestry and Environmental Studies, \\ Western Mindanao State University, Zamboanga City, Philippines, 7000, Philippines
}

Keywords: Elliptic fourier analysis; Variation; Dipterocarps; Pentacme; Shorea.

The Dipterocarpaceae is the only timber-producing taxon in the angiosperm, and it is the most important source of timber in Southeast Asia (Soerianegara and Lemmens, 1993). Dipterocarp trees are influential in their structure and function (Brearley et al., 2017). Dipterocarps are highly productive (Banin et al., 2014) and important storage of above-ground carbon (Slik et al., 2013). The taxonomy of several genera of Dipterocarpaceae is relatively well defined but the genus Shorea remains problematic and has proved most controversial (Maury-Lechon and Curtet, 1998). In the Philippines, there are about 45 species of dipterocarps distributed in 6 genera (Rojo and Aragones Jr, 1997). It has been well-studied but the identities of individual species remain ambiguous (Rojo and Aragones Jr, 1997).

In Mindanao, a species locally known as "malacayan blanco" was originally described by Foxworthy (1938) from Zamboanga Province, and named as Pentacme mindanensis. Based on Foxworthy's description, $P$. mindanensis has resemblance with Shorea contorta but differs in its large leaves and large fruits. However, Ashton (1978) treated $P$. mindanensis as a synonym of $S$. contorta, an island endemic, commonest, and widely distributed dipterocarp species (Foxworthy, 1938; Rojo and Aragones Jr, 1997). Furthermore, there are few detailed morphological, anatomical (Pulan and Buot, 2014), and molecular (Umali, 2016; Villarin et al., 2016) studies on $S$. contorta. Until recently, Umali (2016) confirmed through molecular characterization that $S$. contorta and $P$. mindanensis are two different species. Generally, the recent advancement in biosystematics using DNA sequences has provided evidences to the resolution in the correct classification of many dubious taxon. However, doubts to the reliability of the system arises because many species with very obvious morphological dissimilarities were merged and considered into one species, for instance, Ficus latsonii Elmer and Ficus variegata Blume of Moraceae, the former having a distinct brown-orange trunk while the later has whitish. Also, for the species Melicope monophylla Merr. and Melicope triphylla (Lam.) Merr. of Rutaceae, the former with simple leaf while the latter having a compound one. In this present study, our longstanding knowledge on these species aside from differing fruits and leaf sizes was based mainly on the color of the inner bark with $P$. mindanensis having a cream-yellow while $S$. contorta has white. Thus, in support to the work of Umali (2016), we aim to provide more striking differences via leaf morphometrics. Leaf morphometrics has proved to be effective in resolving taxonomic problems and discriminating species.

*Corresponding author, E-mail: keanmaze@gmail.com

${ }^{1}$ Forest Biological Sciences Department, College of Forestry and Environmental Science, Central Mindanao University, Bukidnon, Philippines, 8714, Philippines. 
The leaves of $S$. contorta and $P$. mindanensis were collected from the Forest Reservation of Western Mindanao State University, Upper La Paz, Zamboanga City, Philippines (Fig. 1). Geographically, it lies between $7^{\circ} 01^{\prime}$ to $7^{\circ} 06^{\prime}$ latitude and $121^{\circ} 58^{\prime} 30^{\prime \prime}$ to $122^{\circ} 02^{\prime} 30^{\prime \prime}$ longitude. Thirty (30) fully expanded, mature and non-damage leaves were collected at the first branch from 10 individuals (five trees per species). The identification of the species was based on the key to the Philippine species of Pentacme by Foxworthy (1918) and from the work of Fernando (2009) and Rojo and Aragones Jr. (1997). The abaxial leaf surface of the specimen was directly overhead with a Canon EOS 70D digital camera. The images were converted into black-and-white contour bitmaps in Microsoft Paint Tools. A software package SHAPE ver. 1.3 (Iwata, 2006) was used to execute Elliptic Fouries Analysis (EFA). Leaf images were converted to binary with the Chain Coder program to obtain the geometry of the shape. Then, the chain code was transformed into Normalized Elliptic Fourier file with the Chc 2 Nef program using the first 20 harmonics to reconstruct the leaf outline. Principal component analysis (PCA) was performed with the Prin Comp program using the Normalized Elliptic Fourier coefficients. The difrefences in leaf outline shape were evaluated and subjected to multivariate analysis of variance (MANOVA) and Linear Discriminant Analysis (LDA). Wilk' lambda criterion for MANOVA and pairwise comparison using Hotelling's Test with Bonferroni's correction were performed. All statistical analysis was done using the Paleontological Statistics (PAST) software version 4.02.

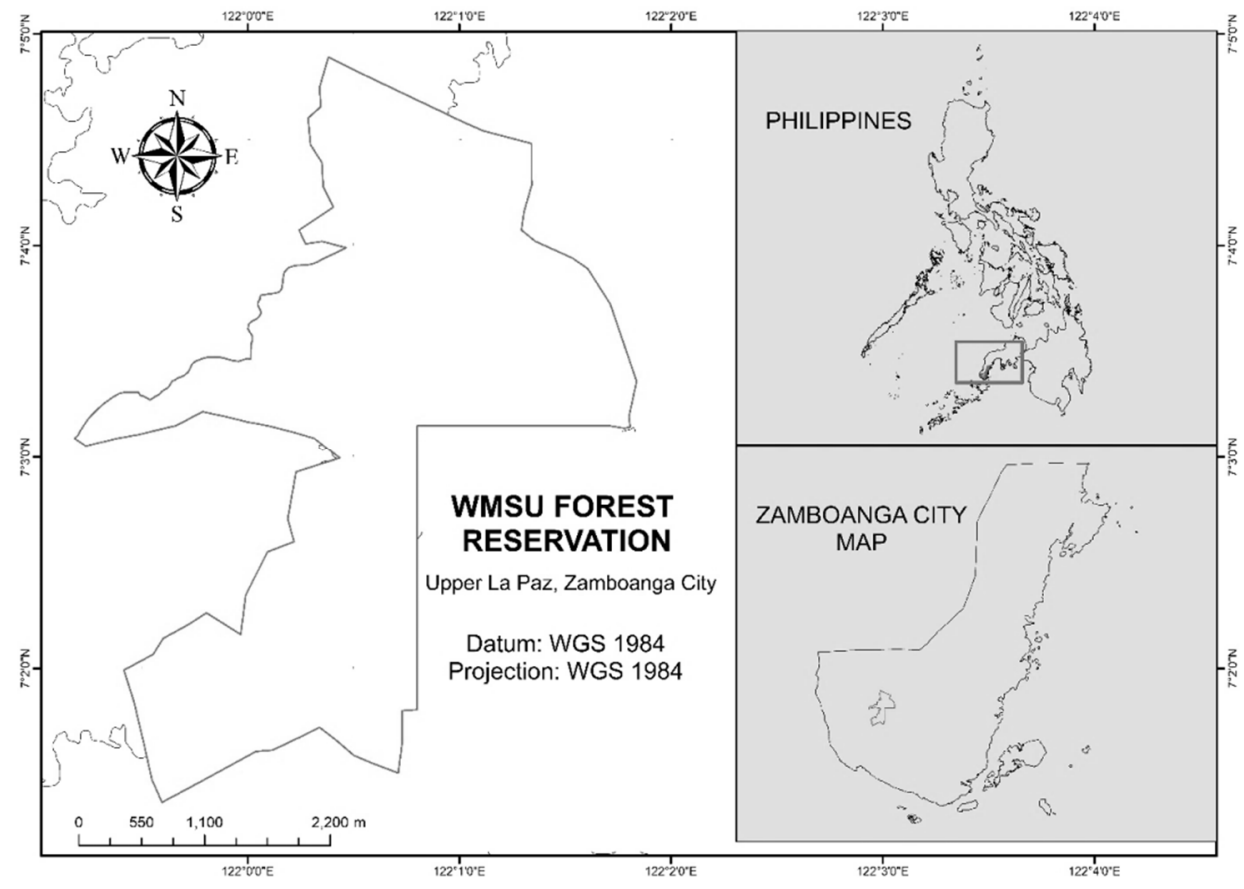

Fig. 1. Location of the study site.

The leaf shape outline variations of $P$. mindanensis and $S$. contorta were described by the first 6 PCs which accounted for $91.66 \%$ of the total variance (Table 1). Fig. 2 explains $47.12 \%$ and $17.57 \%$ of the total variance based from PC 1 and PC 2, respectively, and shows the effect of shape on each PC. The analysis of PC was based on variance co-variance matrix from Elliptic Fourier coefficients. The first PC describes the changes in the proximal and distal portion of the 
leaf samples which result to oblong-lanceolate to ovate variation. PC 2 explains the variation along the middle and apical regions, while PC 3 was related to the variation in the basal to the proximal and fine changes in distal to the apical region. PC 4 describes the fine variations of the leaf outline. PC 5 was characterized by the change in the apices of leaf samples from acute to acuminate, whereas PC 6 is related to the insignificant finer variations along the lamina of the leaf (Fig. 3). Considerable significant differences in the leaf shape outlines derived from effective PCs were also observed. The finding suggests that the variations in leaf shapes between two taxa are supported by their leaf differences according to Foxworthy (1918).

Table 1. Leaf shape variability based on the $1^{\text {st }} 6$ principal components.

\begin{tabular}{cccc}
\hline PCs & Eigenvalue & $\begin{array}{c}\text { Proportion } \\
(\%)\end{array}$ & $\begin{array}{c}\text { Cumulative } \\
(\%)\end{array}$ \\
\hline 1 & $7.41 \times 10^{-04}$ & 49.12 & 49.12 \\
2 & $2.65 \times 10^{-04}$ & 17.57 & 66.69 \\
3 & $2.23 \times 10^{-04}$ & 14.75 & 81.44 \\
4 & $6.88 \times 10^{-05}$ & 4.56 & 86.00 \\
5 & $6.06 \times 10^{-05}$ & 4.01 & 90.01 \\
6 & $2.49 \times 10^{-05}$ & 1.65 & 91.66 \\
\hline
\end{tabular}

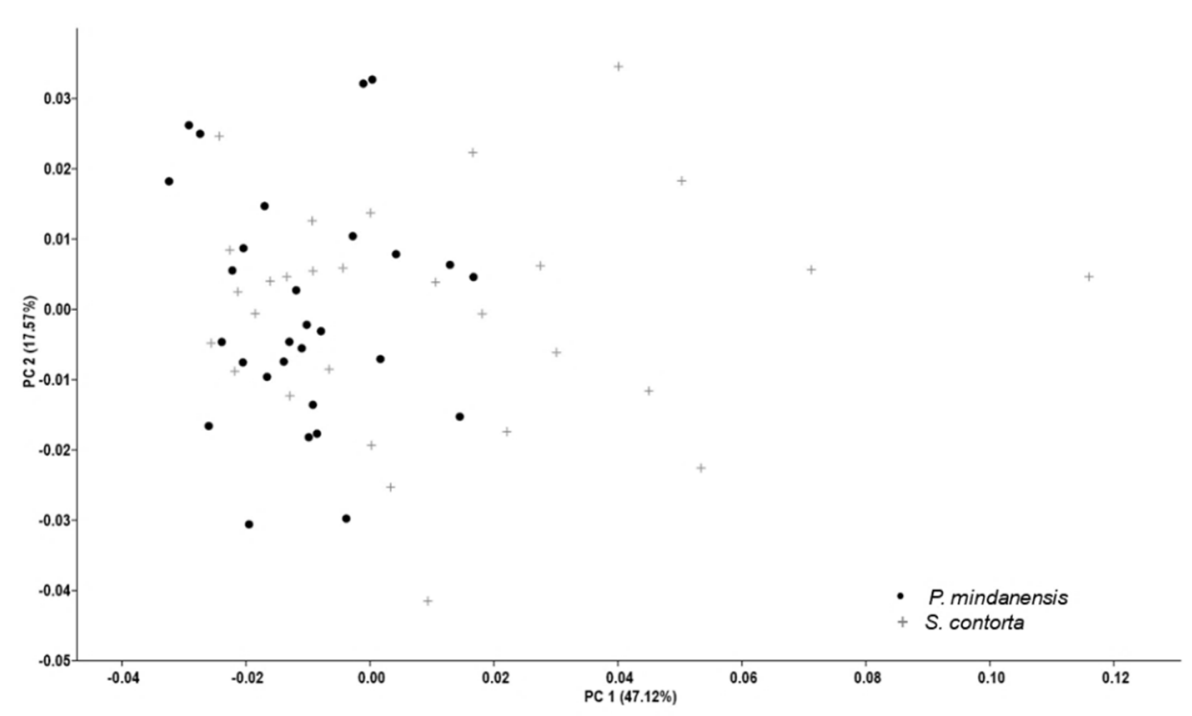

Fig. 2. Principal components of the leaf shape outline.

The results of the LDA of the leaf shape of P. mindanensis and S. contorta based on 6 principal components derived from elliptic Fourier data was shown in Figure 2. Significant differences in the leaf shape were also observed (paired Hoteling's $\mathrm{T}^{2}=86.67 ; F=11.86 ; P=4.62$ x $10^{-6}$ ), with $91.38 \%$ between two taxa were correctly classified. Multivariate analysis of variance showed significant differences wherein leaf shapes were observed between $P$. mindanensis and $S$. contorta $\left(\right.$ Wilks' lambda $=0.42 ; P=3.20 \times 10^{-8} ;$ Pillai trace $=0.58 ; P=3.20 \times 10^{-8}$ ). Leaf shapes 
of $S$. contorta along the discriminant function axis mainly distributed with scores of -10 to 0 showed small overlap with $P$. mindanensis.

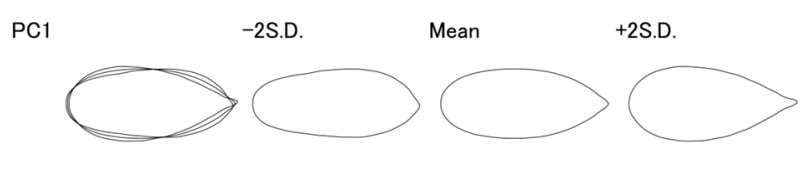

PC2

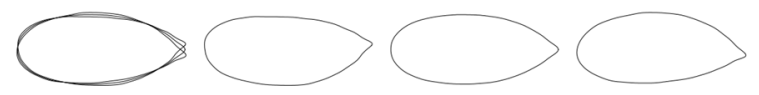

PC3

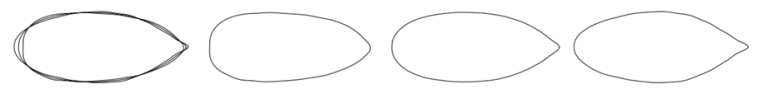

PC4

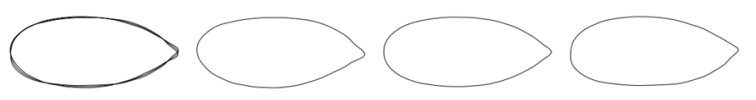

PC5

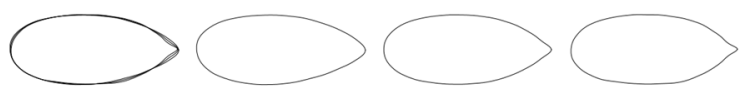

PG6

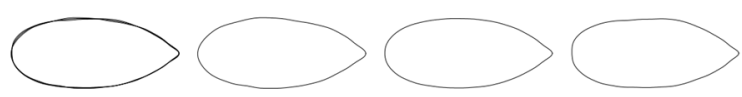

Fig. 3. Reconstruction contour of leaf shape outline variations described by the first 6 PCs.

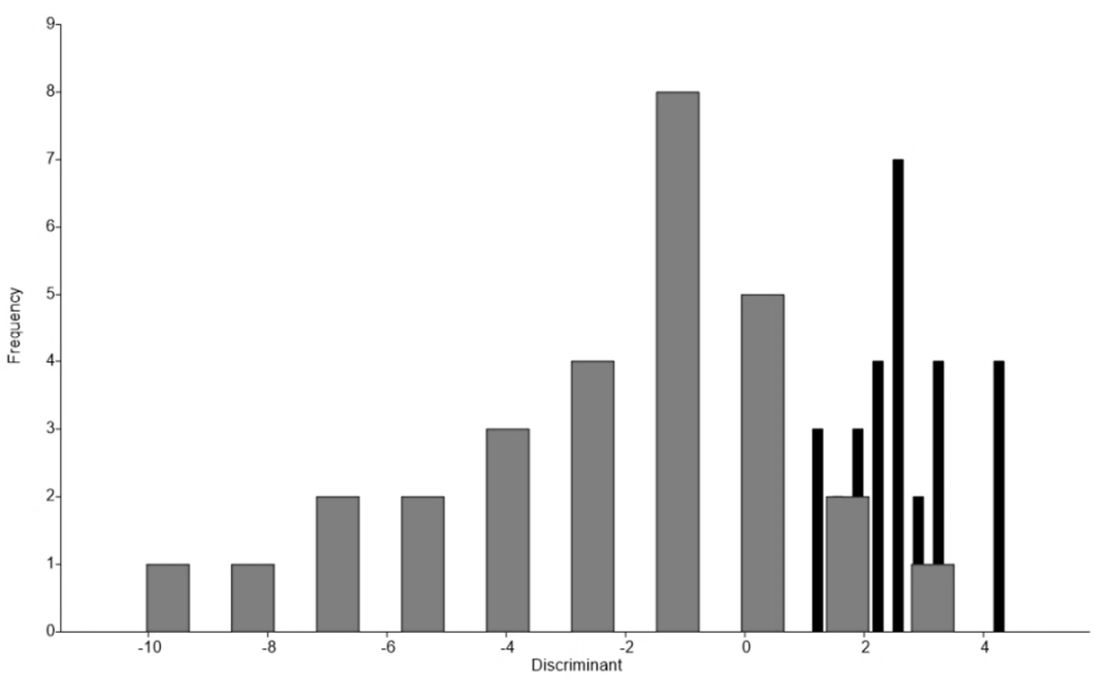

Fig. 4. LDA of leaf shape between P. mindanensis (black bars) and S. contorta (gray bars). 
The comparison of leaf shape outline with the leaf contour between $P$. mindanensis and $S$. contorta using EFA showed consistent significant differences. The results of the MANOVA and LDA in comparing the two taxa further revealed that the leaf shape could help in discriminating $P$. mindanensis and S. contorta without considering the leaf sizes. $91.38 \%$ of the leaf samples were correctly assigned to their taxa. However, leaf shape widely varies among dipterocarp species (Brearley et al., 2017; Ghazoul, 2016; Maury-Lechon and Curtet, 1998) which are mainly attributed by environmental and genetic factors. The small overlap that was noted between two taxa could perhaps explain their genetic background and environmental conditions.

\section{Acknowledgement}

We thank the Department of Science and Technology-Science Education Institute (DOSTSEI) for the financial support and to the Center of Upland and Ecosystem Management (CUEM) of Western Mindanao State University (WMSU) for the permission to conduct this study.

\section{References}

Ashton, P. 1978. Flora Malesiana Precursores: Dipterocarpaceae. Gardens’ Bulletin, Singapore, 31: 5-48. DOI: $=$ org/10.3897/ab.e1141

Banin, L, Lewis S.L., Lopez-Gonzalez, G., Baker, T.R., Quesada, C.A., Chao, K.J. and Phillips, O.L. 2014. Tropical forest wood production: A cross-continental comparison. Journal of Ecology, 102(4): 10251037. DOI:.org/10.1111/1365-2745.12263

Brearley, F.Q., Banin, L.F. and Saner, P. 2017. The ecology of the Asian dipterocarps. Plant Ecology \& Diversity, 9(5-6), 429-436. DOI: org/10.1080/17550874.2017.1285363

Fernando, E.S. 2009. Habitats of Philippine Dipterocarps. Soil and Water Conservation Foundation.

Foxworthy, F.W. 1918. Philippine Dipterocarpaceae II. Philippine Journal of Science of Science, 8(3): 163199.

Foxworthy, F.W. 1938. Philippine Dipterocarpaceae III. Philippine Journal of Science, 67: 241-333.

Ghazoul, J. 2016. Dipterocarp Biology, Ecology, and Conservation. Oxford University Press, New York, Iwata, H. 2006. SHAPE. National Agricultural Research Organization.

Maury-Lechon, G. and Curtet, L. 1998. Biogeography and Evolutionary Systematics of Dipterocarpaceae. In: A Review of Dipterocarps: Taxonomy, ecology and silviculture, pp. 5-44.

Pulan, D.E. and Buot, I.E. 2014. Leaf Architecture of Philippine Shorea species (Dipterocarpaceae). International Research Journal of Biological Sciences 35:19-26.

Rojo, J.P. and Aragones Jr., E.G. 1997. Botanical Indentification Handbook on Philippine Dipterocarps. Technology, Forest Products Research and Development (FRDI) Department of Science and Technology.

Slik, J.W.F., Paoli, G. and Mcguire, K. 2013. Large trees drive forest aboveground biomass variation in moist lowland forests across the tropics. Global Ecology and Biogeography, 22(12): 1261-1271. DOI:.org/10.1111/geb.12092

Soerianegara, I. and Lemmens, R.H. 1993. Timber trees: major commercial timbers. Plant Resources in Southeast Asia, 5(1).

Umali, A.G. 2016. Taxonomic characterization of Philippine dipterocarps, [Thesis] University of the Philippines-Los Banos

Villarin, R., Prinz, K., Patindol, T. and Finkeldey, R. 2016 Cross-species Amplification and Characterization of Shorea Microsatellites in Shorea contorta Vidal (Dipterocarpaceae). Journal of Society \& Technology, 6: 55-62. 